\title{
Rinsing/Washing Method of Administration
}

National Cancer Institute

\section{Source}

National Cancer Institute. Rinsing/Washing Method of Administration. NCI Thesaurus.

Code C149887.

The technique of administration of a pharmaceutical product by bringing it into contact with the affected area for a short period of time, e.g. by pouring it over the area and allowing it to drain away, or swilling it around the area and then removing it. 